\title{
PENGEMBANGAN FASILITAS KURSI BELAJAR YANG ERGONOMIS DAN ANTROPOMETRI UNTUK ANAK HIPERAKTIF DI SEKOLAH INKLUSI
}

\author{
Hartini Laswandi ${ }^{1}$, Heni Mularsih (Almrh) ${ }^{2}$ \\ ${ }^{1}$ Desain Interior, Universitas Tarumanagara Jakarta \\ Email: hartini@fsrd.untar.ac.id \\ ${ }^{2}$ Fakultas Psikologi, Universitas Tarumanagara, Jakarta \\ Email:henim@mku.untar.ac.id
}

\begin{abstract}
There are complaints of discomfort and difficulty in dealing with the activeness of hyperactive students felt in inclusive elementary schools. Anxious attitude when sitting, always disturbing friends while learning is taking place, this can interfere with the learning process, both for other normal students and hyperactive students. The purpose of this research is to develop a special study chair design for hyperactive students that is ergonomic based on anthropometry. The method used in this research is an ergonomic approach to the anthropometric method and the design method that prioritizes quality. Develop ergonomic and anthropometric chair products based on devine, design and develop procedures. This approach is used to determine the dimensions of the chair design. Study chair facilities that are ergonomic and anthropometric in learning need to be developed in every school, both public and inclusive schools. Guidelines for the design of activities and facilities for hyperactive students during learning activities, based on the analysis of activities and facilities for hyperactive students in inclusive schools. The design result of the development of a special study chair for hyperactive students is a chair design with adjustable armrests, flexible chairs and footrests with a slider system that can answer user complaints. Chair design with armrests, flexible and strong footrests can provide comfort for hyperactive students and reduce their activity. Inclusion schools are expected to facilitate learning facilities, especially for students with special needs.
\end{abstract}

Keywords: Hyperactive students, inclusive schools, ergonomics anthropometry, design, study chairs

\begin{abstract}
ABSTRAK
Adanya keluhan ketidaknyamanan dan kesulitan dalam menghadapi keaktifan siswa hiperaktif dirasakan di sekolah dasar inklusi. Sikap cemas saat duduk, selalu mengganggu teman saat belajar berlangsung hal ini dapat mengganggu proses belajar, baik untuk siswa normal lainnya maupun siswa hiperaktif. Tujuan dari penelitian ini adalah untuk mengembangkan desain kursi belajar khusus untuk siswa hiperaktif yang ergonomis berdasarkan antropometri. Metode yang digunakan dalam penelitian adalah pendekatan ergonomi terhadap metode antropometri dan metode desain yang mengutamakan kualitas. Mengembangkan produk kursi yang ergonomis dan antropometris berdasarkan dengan prosedur devine, design, dan develop. Pendekatan ini digunakan untuk menentukan dimensi desain kursi. Fasilitas kursi belajar yang ergonomi dan antropometri dalam pembelajaran perlu dikembangkan di setiap sekolah, baik sekolah umum maupun sekolah inklusi Pedoman desain aktivitas dan fasilitas siswa hiperaktif saat kegiatan belajar, berdasarkan analisis aktivitas dan fasilitas siswa hiperaktif di sekolah inklusi. Hasil desain dari pengembangan kursi belajar khusus untuk siswa hiperaktif adalah desain kursi dengan sandaran tangan yang bisa disetel, kursi yang fleksibel dan sandaran kaki dengan sistem slider dapat menjawab keluhan pengguna. Desain kursi dengan sandaran tangan, pijakan kaki yang lentur dan kuat dapat memberikan kenyamanan bagi siswa hiperaktif dan mengurangi keaktifannya. Sekolah inklusi diharapkan untuk memfasilitasi sarana belajar terutama bagi siswa berkebutuhan khusus ini.
\end{abstract}

Kata Kunci: Siswa hiperaktif, sekolah inklusif, antropometri ergonomi, desain, kursi belajar

\section{PENDAHULUAN}

Fasilitas kursi belajar yang ergonomi dan antropometri dalam pembelajaran perlu dikembangkan di setiap sekolah, baik sekolah umum maupun sekolah inklusi, dari tingkat sekolah dasar, sekolah menengah dan sekolah atas. Perencanaan dan pengembangan fasilitas kursi belajar meliputi pendataan aktivitas dan kebutuhannya saat pembelajaran. Pengembangan mulai dari identifikasi kebutuhan belajar, analisis pengembangan desain, proses sintesis yang menghasilkan konsep 
programatik, selanjutnya adalah konsep desain, dan implementasi desain ke dalam gambar desain. Menganalisis aktivitas dan perilaku belajar siswa hiperaktif seperti karakter, kebiasaan atau emosi siswa hiperaktif untuk menerjemahkan menjadi desain kursi belajar yang ergonomis dan antropometris.

Hasil penelitian sebelumnya, belum ditemukan adanya desain pengembangan kursi belajar khusus bagi siswa hiperaktif yang ergonomis dan antropometri sehingga nyaman, aman saat posisi duduk. Team peneliti tertarik dan perlu melakukan penelitian pengembangan desain kursi belajar khusus bagi siswa hiperaktif di sekolah inklusi. Anak-anak menghabiskan banyak waktu duduk di kelas. Siswa sekolah dasar beraktivitas duduk di kursi, mendengarkan, berbicara, membaca dan menulis (5 hari dalam seminggu), sehingga kenyamanan kursi belajar memiliki dampak besar (Ismaila et al., 2013).

Sekolah umum yang menerima siswa inklusif, saat ini belum memberikan fasilitas kursi belajar bagi siswa inklusif yang ergonomis dan antropometri. Kesalahan kursi belajar yang dijumpai bagi siswa inklusif, antara lain: (a) pola postur pada tempat duduk kelas dirancang untuk siswa normal yaitu kursi untuk postur tegak. Kursi belajar jenis ini dapat menciptakan jumlah aktivitas otot yang berlebihan. Siswa hiperaktif yang duduk pada kursi ini menjadi kurang nyaman dan kurang sehat; (b) anak hiperaktif karakternya banyak bergerak sehingga perlu ukuran dan desain yang flexible, perlu kekuatan, dan kemampuan kognitif berbeda; (c) siswa hiperaktif menggunakan fasilitas kursi belajar yang sama dengan siswa normal saat ini, yang tidak memenuhi standar ergonomis sehingga menyebabkan gejala stres fisik yang sangat nyata. Desain kursi belajar yang tidak ergonomis dapat menyebabkan sirkulasi darah kurang lancar; kurang relax/tegang, gangguan otot leher dan punggung; dan (d) fasilitas kursi belajar bagi siswa hiperaktif yang belum tersedia dan sama dengan siswa normal secara ergonomis juga berdampak pada ergonomi kognitif siswa hiperaktif, yaitu bagaimana pikiran siswa bekerja serta proses mental selalu gelisah. Fasilitas kursi belajar di sekolah umum saat digunakan untuk siswa hiperaktif juga tidak disesuaikan dengan ukuran dimensi yang dibutuhkan siswa. Sehingga, fasilitas kursi belajar bagi siswa inklusif tidak dapat digunakan dalam jangka waktu yang lama. Keadaan seperti ini merupakan gambaran kurangnya perhatian, konsentrasi yang buruk, memori yang buruk dan tingkat pencapaian yang lebih rendah. Guru dan siswa normal lain juga terdampak. Dari banyaknya permasalahan di atas, peneliti perlu untuk mengembangkan fasilitas kursi belajar bagi siswa hiperaktif. Penelitian pengembangan desain ini bertujuan untuk memfasilitasi belajar bagi siswa hiperaktif antara dimensi tubuh dan analisa kegiatan duduk saat pembelajaran di sekolah dasar inklusi di Indonesia, yaitu Fasilitas Kursi Belajar yang Ergonomi dan Antropometri.

Fasilitas kursi belajar belum sepenuhnya mendukung proses pembelajaran secara efektif dan memfasilitasi pengembangan lingkungan belajar bagi siswa dan guru dalam mencapai tujuan belajar. Siswa berkegiatan duduk pada banyak posisi berbeda seperti posisi tegak, bungkuk, memutar, miring, dan sebagainya. Mereka merentangkan kaki, duduk di atasnya, menyilangkannya, memantulkannya. Penelitian yang dilakukan oleh pakar yang diakui dalam mengukur kinerja pekerja, ergonomi, perilaku dan lingkungan. (Enjoh, 2018; Hanggara et al., 2019).

Fasilitas kursi belajar perlu diskalakan dengan baik agar sesuai dengan ukuran masing-masing siswa. Fasilitas fisik sekolah berpengaruh pada lingkungan belajar dan hasil belajar siswa (Nepal \& Maharjan, 2015). Kurangnya fasilitas akan mengarah pada kinerja pembelajaran yang buruk di lingkungan sekolah (Ilomo \& Mlavi, 2016). Siswa cenderung lebih menyukai pengaturan tempat duduk yang lebih fleksibel. Menempatkan kursi yang dinamis menjadi artefak pedagogis dalam 
proses desain partisipatif, bagaimana pendidik dan siswa menciptakan ruang belajar yang fungsional dan bermakna (Kallio, 2018). Menurut Adigeb et al. (2017), belajar dipengaruhi oleh berbagai karakteristik fisik kelas, diantaranya adalah gaya kursi. Gaya kursi yang benar secara ergonomis merupakan elemen penting dalam lingkungan pembelajaran fisik, karena populasi siswa berubah dalam hal bentuk dan ukuran tubuh (Chan, 2009) memperkuat pentingnya ergonomis. Fasilitas kursi belajar yang ergonomis dan antropometri dapat memupuk siswa dalam kerja tim dan kolaborasi di kelas, tidak terkecuali bagi siswa hiperaktif. Siswa hiperaktif melalui fasilitas kursi yang khusus dapat mengakomodasi kegiatan belajar yang berbeda (Ibrahim et al, 2016). Anak Hiperaktif tidak mampu berkonsentrasi dan cenderung melupakan apa yang telah didengarkan dan dikatakan terhadapnya kurang dari 10 detik, tidak mampu diam, bertindak sesuka hatinya dan susah untuk diberi nasehat (Merril, et al, 2017).

Sekolah inklusi dalam penyelenggaraan pendidikan dengan menyatukan anak-anak berkebutuhan khusus dengan anak-anak normal pada umumnya. Siswa berkebutuhan khusus juga berkeinginan menempuh pendidikan yang lebih tinggi. Siswa yang belajar di sekolah inklusi membutuhkan fasilitas kursi belajar yang dapat mengimbangi aktivitas pembelajaran yang baik. Penelitian pengembangan fasilitas belajar telah dilakukan, dan sarannya agar terus dilakukan inovasi untuk perbaikan terus menerus, oleh (Morieson et al., 2018).

Kursi belajar antropometri dipakai untuk mengukur data-data antropometri siswa dalam posisi duduk saat belajar. Fasilitas kursi belajar yang kurang mempertimbangkan ergonomis dan antropometri akan tidak nyaman di punggung dan menyebabkan gangguan muskuloskeletal (Renaud et al., 2019). Penyelidikan ukuran antropometri terkait seperti tinggi badan, berat badan, Indeks Massa Tubuh (IMT), tinggi poplitea, panjang poplitea bokong dan napas pinggul.

Pengukuran antropometri digunakan sebagai kata kunci dalam mendesain furnitur secara ergonomis. Langkah-langkah antropometri dikumpulkan ke posisi duduk dan berdiri siswa hiperaktif di meja belajar yang terdiri dari: (a) ketinggian duduk, dihitung dengan jarak vertikal dari permukaan duduk horizontal ke titik tinggi kepala. Ini digunakan untuk mengetahui jarak bebas vertikal yang diperlukan untuk postur duduk; (b) tinggi mata duduk, dihitung dengan jarak vertikal dari permukaan duduk horizontal ke mata. Tampilan visual harus diposisikan di bawah bidang horizontal yang ditentukan oleh ketinggian mata; (c) tinggi bahu duduk, dihitung dengan jarak vertikal dari permukaan duduk horisontal ke akromion.

Ergonomi menurut Ginting (2010) adalah suatu cabang keilmuan yang sistematis untuk memanfaatkan informasi mengenai sifat, kemampuan dan keterbatasan manusia dalam merancang suatu sistem kerja, sehingga orang dapat hidup dan juga bekerja pada suatu sistem yang baik yaitu untuk mencapai tujuan yang diinginkan dengan melalui pekerjaan yang efektif, efisien, aman dan nyaman. Menurut Wignjosoebroto (2008), antropometri adalah studi yang berkaitan dengan pengukuran dimensi tubuh manusia. Bidang antropometri meliputi berbagai ukuran tubuh manusia seperti berat badan, posisi ketika berdiri, ketika merentangkan tangan, lingkar tubuh, panjang tungkai, dan sebagainya.

\section{METODE PENELITIAN}

Objek Penelitian adalah siswa sekolah inklusi dipilih secara acak baik yang normal maupun yang hiperaktif untuk melakukan pengumpulan data. Data kebutuhan aktivitas dan fasilitas disiapkan untuk mengidentifikasi permasalahan dalam pemenuhan fasilitas belajar siswa. Metode desain dengan digunakan untuk memprioritaskan persyaratan desain. Berbagai jenis pengukuran antropometri dibahas untuk memahami pengumpulan data. Langkah-langkah proses desain kursi 
belajar siswa hiperaktif dibahas. Prosedur perhitungan ketidakcocokan antara dimensi furnitur dan tubuh juga ditampilkan. Analisis dilakukan dengan menggunakan metode desain untuk membantu perancang dalam menyusun pedoman desain dan konsep desain. Mengembangkan produk kursi yang ergonomis dan antropometris berdasarkan dengan prosedur devine, design, dan develop. Berupa pengembangan desain kursi dengan tahap devine (menetapkan perancangan), design (perencanaan desain, penetapan konsep desain), develop (hasil desain) (Ekundayo \& Timilehin, 2012).

\section{HASIL DAN PEMBAHASAN}

\section{Hasil pedoman desain}

Pedoman desain aktivitas dan fasilitas siswa hiperaktif saat kegiatan belajar, berdasarkan analisis aktivitas dan fasilitas siswa hiperaktif di sekolah inklusi dapat dilihat pada tabel 2. Dimensi kursi sesuai ergonomi dan antropometri yang ideal dapat dilihat pada tabel 3.

Tabel 1. Pedoman Desain Aktivitas dan Fasilitas Siswa Hiperaktif

\begin{tabular}{|c|c|c|c|}
\hline $\begin{array}{l}\text { Inclusive } \\
\text { Students }\end{array}$ & $\begin{array}{c}\text { Aktivitas siswa hiperaktif saat } \\
\text { belajar }\end{array}$ & Cara mengatasi & $\begin{array}{c}\text { Pedoman Desain } \\
\text { dalam pengembangan }\end{array}$ \\
\hline \multirow[t]{5}{*}{$\begin{array}{l}\text { Hiperaktif/ } \\
\text { ADHD }\end{array}$} & $\begin{array}{l}\text { - Tidak Fokus } \\
\text { - Belajar tidak bisa bertahan lama. } \\
\text { - Suka merebut perlengkapan } \\
\text { teman lain. } \\
\text { - Ikut bermain bersama siswa lain. } \\
\text { - Begitu ada anak lain yang } \\
\text { berbeda, dia mengikuti anak } \\
\text { tersebut. } \\
\text { - Anak hiperaktif bertahan diam } \\
\text { tidak lebih dari } 5 \text { menit. } \\
\text { - Anak suka berteriak-teriak tidak } \\
\text { jelas, dan berbicara semaunya. } \\
\text { - Bersikap seenaknya }\end{array}$ & $\begin{array}{l}\text { - Konsentrasi perlu dilatih. } \\
\text { - Pikiran harus diarahkan ke } \\
\text { suatu titik dalam suatu } \\
\text { pelajaran. } \\
\text { - Membantu anak untuk dapat } \\
\text { fokus dan berkonsentrasi. } \\
\text { - Mengeliminasi atau } \\
\text { mengurangi kesulitan belajar } \\
\text { dengan peduli factor apa yang } \\
\text { mengakibatkan kesulitan } \\
\text { belajar siswa. } \\
\text { - Latih lah secara berulang-ulang. }\end{array}$ & \\
\hline & $\begin{array}{l}\text { - Sifat Menentang } \\
\text { - Anak hiperaktif lebih sulit } \\
\text { dinasehati. } \\
\text { - Bermain semaunya sendiri. } \\
\text { - Diam saja atau mudah sedih. } \\
\text { - Mudah Marah dengan tetap } \\
\text { melanjutkan bermain }\end{array}$ & $\begin{array}{l}\text { Konselor Sekolah } \\
\text { mendampinginya. } \\
\text { - Dibangun komunikasi dua arah }\end{array}$ & 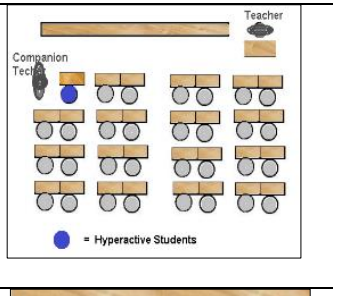 \\
\hline & $\begin{array}{l}\text { - Destruktif } \\
\text { - Sebagai perusak benda-benda } \\
\text { disekitarnya atau barang pecah } \\
\text { belah. } \\
\text { - Sikap suka melempar. } \\
\text { - Suka menghancurkan barang }\end{array}$ & $\begin{array}{l}\text { Memperhatikan suasana hati } \\
\text { anak. } \\
\text { - Menghindarkan siswa dari } \\
\text { benda yang membahayakan } \\
\text { - Menghilangkan rangsangan } \\
\text { agresif seperti meniadakan } \\
\text { tontonan kekerasan, } \\
\text { kebrutalan, dsb } \\
\text { - Mengembangkan sikap empati } \\
\text { pada anak }\end{array}$ & \\
\hline & $\begin{array}{l}\text { - Tidak Mengenal Lelah } \\
\text { - Setiap hari berlari, berjalan dan } \\
\text { melakukan kegiatan tanpa tujuan } \\
\text { jelas, } \\
\text { - Bergerak terus }\end{array}$ & $\begin{array}{l}\text { Guru mengarahkan kepada } \\
\text { tindakan belajar yang positif. } \\
\text { Menerima dan memahami } \\
\text { pribadi anak }\end{array}$ & Teacrier \\
\hline & $\begin{array}{l}\text { Belajar Tanpa Tujuan Jelas; kadang } \\
\text { baca buku, menyobek buku, } \\
\text { melipat-lipat, atau dibolak balik } \\
\text { saja }\end{array}$ & $\begin{array}{l}\text { - Menjalin hubungan yang } \\
\text { harmonis dengan siswa }\end{array}$ & $\begin{array}{l}\text { Companion } \\
\text { Teacher }\end{array}$ \\
\hline
\end{tabular}




\begin{tabular}{ll}
\hline Tidak sabar & Peka terhadap kebutuhan anak. \\
Usil saat belajar, merebut & Ciptakan PAKEM (pembelajaran \\
perlengkapan teman. & aktif, kreatif, efektif dan \\
Tidak suka menunggu. & menyenangkan), \\
Suka mendorong, mencubit, atau & $\begin{array}{l}\text { Sediakan fasilitas kursi yang } \\
\text { nyaman } \\
\text { memukul tanpa alasan }\end{array}$ \\
&
\end{tabular}

Tabel 2. Dimensi Desain Kursi untuk Siswa Hiperaktif

\begin{tabular}{ll}
\hline \multicolumn{1}{c}{ Posisi } & Dimensi Satuan \\
\hline Lebar dudukan kursi & $41 \mathrm{~cm}-51 \mathrm{~cm}$ \\
Panjang sabuk pengaman & $65 \mathrm{~cm}-75 \mathrm{~cm}$ \\
seat depth & $38.1 \mathrm{~cm}-51 \mathrm{~cm}$ \\
ketinggian kursi dari lantai & $41 \mathrm{~cm}-51 \mathrm{~cm}$ \\
kemiringan kursi depan ke belakang & $12.7 \mathrm{~cm}$ to $8^{\circ}$ \\
tinggi sandaran tangan di atas kursi & $18 \mathrm{~cm}-23 \mathrm{~cm}$ \\
panjang sandaran tangan & $21 \mathrm{~cm}$ \\
lebar sandaran tangan & $5.08 \mathrm{~cm}$ \\
kursi belakang sandaran tangan dari & $5.08 \mathrm{~cm}-7.62 \mathrm{~cm}$ \\
depan & \\
tinggi kursi belakang & $31 \mathrm{~cm}-46 \mathrm{~cm}$ \\
seat back recline angle & $0^{\circ}-5^{\circ}$ \\
Tinggi panjat kaki & $15.24 \mathrm{~cm}-20,32 \mathrm{~cm}$ \\
\hline
\end{tabular}

\section{Hasil Desain Kursi Belajar Bagi Siswa Hiperaktif}

Desain kursi belajar bagi siswa hiperaktif yang diusulkan memiliki dimensi yang sesuai untuk fasilitas belajar yang nyaman dan aman. Pengumpulan data perancangan, analisis pengembangan desain dan gambar desain. Hasil pengembangan desain kursi belajar bagi siswa hiperaktif memiliki sandaran tangan dan penyangga tangan yang dapat diset buka tutup, pijakan kaki kuat tapi lentur untuk menggerak-gerakan kaki, dudukan yang empuk sehingga nyaman pada gambar 1, bagi siswa dengan dimensi badan tinggi dengan desain kaki yang bisa diatur tinggi rendah serta sabuk pengaman jika diperlukan ketika siswa hiperaktif perlu konsentrasi belajar pada desain gambar 2 . Hasil pengembangan Desain kursi belajar bagi siswa hiperaktif setelah melalui proses analisis dapat ditunjukkan pada gambar di bawah ini.

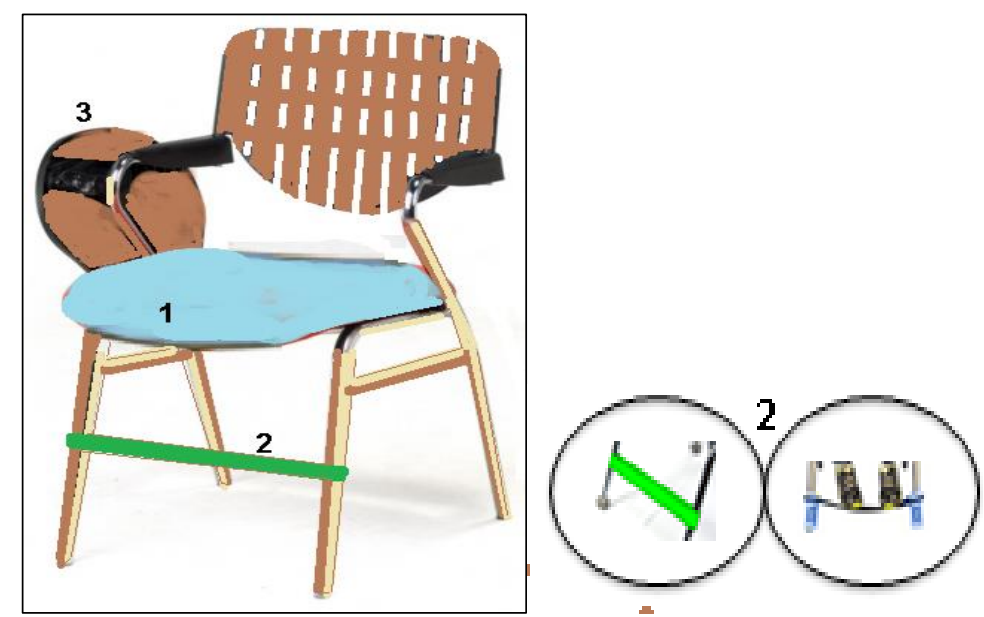

Gambar 1. Desain Kursi Belajar Siswa Hiperaktif 
Keterangan: (a) dudukan kursi yang empuk; (b) pijakan kaki lentur dan kuat dari bahan poliester kualitas tinggi, untuk pijakan kaki siswa hiperaktif yang tidak bisa diam; dan (c) sandaran tangan untuk baca tulis, bisa diset buka tutup.

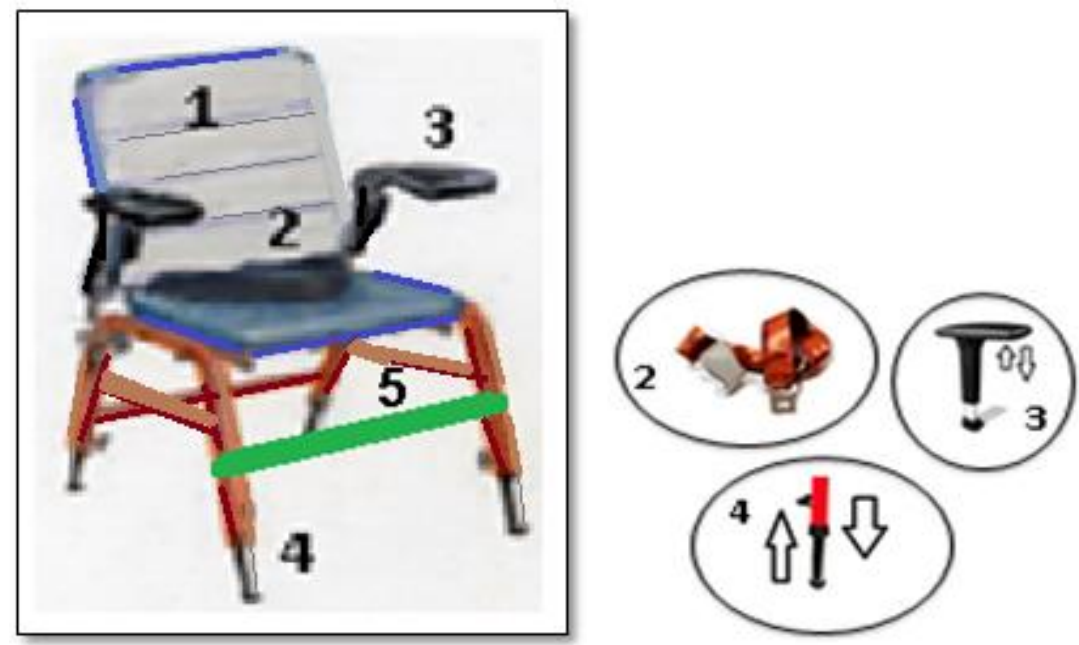

Gambar 2. Desain Kursi Belajar Siswa Hiperaktif

Keterangan: (a) sandaran duduk bahan empuk dan nyaman; (b) sabuk pengaman bisa digunakan secara fleksibel, jika siswa hiperaktif perlu konsentrasi tinggi; (c) sandaran tangan bisa diatur naik turun; (d) kaki yang dapat diatur tinggi rendah sesuai kebutuhan: dan (e) pijakan kaki lentur dan kuat dari bahan poliester kualitas tinggi, untuk pijakan kaki siswa hiperaktif yang tidak bisa diam.

\section{Pembahasan}

\section{Implikasi pengembangan desain kursi belajar bagi siswa hiperaktif}

Furniture kursi belajar untuk siswa hiperaktif penting di sekolah-sekolah inklusi, memberikan dukungan untuk pembelajaran. Untuk desain keselamatan, penting untuk memahami parameter postur siswa hiperaktif dan aktivitas berlebihan secara optimal seperti jarak siku-tanah, ketinggian poplitea dan sudut jangkauan (Bora et al., 2019). Tujuan utamanya adalah untuk berkontribusi pada keberhasilan sekolah inklusi. Untuk tujuan ini, harus terdiri dari: (a) kursi yang sesuai dengan kegiatan belajar sekolah inklusi; (b) kursi yang mendukung gaya belajar siswa hiperaktif; (c) kursi yang memenuhi kebutuhan fisik siswa untuk membantu mereka tetap sehat, nyaman, dan terlibat dalam pembelajaran; dan (e) kursi yang memaksimalkan fungsi untuk belajar bagi siswa hiperaktif.

Fleksibilitas, dalam kemampuan beradaptasi dan mobilitas, desain kursi yang fleksibel, mudah beradaptasi, dan bergerak yang dapat digunakan untuk berbagai aktivitas, dalam pengaturan yang mudah dikonfigurasi ulang seperti baris, kluster dan lingkaran, dan disimpan baik sepanjang hari sekolah maupun dalam jangka panjang untuk mengakomodasi siswa hiperaktif dalam pembelajaran terpusat, kolaboratif dan kelompok, serta kemajuan teknologi dan metode pengajaran.

Ragam, yaitu: (a) desain kursi belajar bagi siswa hiperaktif yang sesuai dengan kebutuhan untuk pekerjaan individu, pekerjaan kelompok, dan interaksi dengan guru; dan (b) desain kursi belajar bagi siswa hiperaktif yang mendukung berbagai keterampilan, gaya, dan kebutuhan belajar. 
Ergonomi antropometri dan kenyamanan, yaitu: (a) kursi belajar bagi siswa hiperaktif yang dirancang agar sesuai secara ergonomis bagi siswa hiperaktif dengan ukuran dan proporsi yang dibutuhkan serta mendukung gaya belajar; (b) kursi belajar bagi siswa hiperaktif yang dirancang untuk meningkatkan kenyamanan, mengurangi perilaku hiperaktif dan konsentrasi untuk periode penggunaan selama di kelas; dan (c) kursi yang menyesuaikan dengan tinggi, berat dan tugas siswa hiperaktif, sehingga nyaman untuk mengikuti pembelajaran dengan tenang.

Kesehatan dan keselamatan, yaitu: (a) kursi belajar bagi siswa hiperaktif yang dapat dibersihkan dan di sanitasi secara teratur karena biasanya memiliki kontak langsung dengan banyak pengguna; (b) kursi belajar bagi siswa hiperaktif yang mengurangi gerakan siswa dan aktivitas fisik. Dengan kursi yang nyaman siswa hiperaktif tidak gelisah saat konsentrasi. dan fokus, berguna bagi kesehatan fisik; (c) pemilihan warna yang tepat untuk kursi belajar bagi siswa hiperaktif tidak hanya membantu menentukan tujuan ketenangan juga membantu siswa menambah stimulasi sensorik dan berdampak pada pembelajaran dan kesehatan. Warna memengaruhi emosi, perhatian, sikap, produktivitas, komunikasi, dan pembelajaran.

Pengembangan desain kursi belajar bagi siswa hiperaktif ini memfasilitasi sarana belajar pada sekolah inklusi yang belum diperhatikan dan disediakan oleh pemangku kepentingan di sekolah inklusi. Kemungkinan ketidaksesuaian antara furnitur kursi belajar dan karakteristik ergonomi antropometri dari siswa hiperaktif di Indonesia. Studi menunjukkan bahwa, dimensi furnitur yang diusulkan lebih tepat dan lebih spesifik daripada furnitur kursi belajar yang ada. Dimensi yang diusulkan untuk furnitur kursi belajar bagi siswa hiperaktif terdapat spesifikasi terutama pada sandaran tangan, dudukan terdapat sabuk pengaman dan kaki kursi terdapat tali lentur yang kuat untuk gerakan kaki yang aktif. Jadi, desain kursi belajar bagi siswa hiperaktif di sekolah dasar inklusi yang dimodifikasi akan sesuai untuk kebutuhan siswa hiperaktif dengan dimensi yang fleksibel untuk siswa yang gemuk, sedang atau kurus.

\section{KESIMPULAN DAN SARAN}

Penelitian pengembangan desain ini bertujuan untuk memfasilitasi desain kursi belajar bagi siswa hiperaktif antara dimensi tubuh dan analisa kegiatan duduk saat pembelajaran di sekolah dasar inklusi di Indonesia, dan desain kursi belajar bagi siswa hiperaktif yang ergonomis. Belum ketersediaan kursi belajar bagi siswa hiperaktif diidentifikasi di sekolah dasar inklusi di Indonesia. Pengembangan desain kursi belajar bagi siswa hiperaktif terdapat beberapa spesifikasi yang perlu ada. Desain kursi bagi siswa hiperaktif memiliki sandaran tangan dan penyangga lumbar yang dapat diatur naik turun, pijakan kaki kuat tapi lentur untuk menggerak-gerakan kaki, dudukan sensorik yang empuk sehingga nyaman, bagi siswa dengan dimensi badan tinggi dengan desain kaki yang bisa diatur tinggi rendah serta sabuk pengaman jika diperlukan ketika siswa hiperaktif perlu konsentrasi belajar. Temuan penelitian ini juga menunjukkan dengan jelas bahwa desain kursi belajar bagi siswa hiperaktif pada sekolah inklusi di Indonesia harus dibuat sesuai dengan penilaian ergonomi antropometri untuk memenuhi kebutuhan aktivitas duduk saat proses pembelajaran di kelas. Desain kursi belajar bagi siswa hiperaktif diupayakan agar nyaman, aman dan mendukung konsentrasi siswa hiperaktif saat belajar di kelas.

\section{Ucapan Terima Kasih (Acknowledgement)}

Peneliti mengucapkan terima kasih kepada kepala sekolah, para guru di SD Inklusi Negeri dan Swasta yang telah bersedia untuk berpartisipasi dalam seluruh proses dalam penelitian ini. Penulis juga mengucapkan terima kasih kepada Universitas Tarumanagara Jakarta atas dukungan dalam penelitian ini. 


\section{REFERENSI}

Adigeb, P. A., Anake P. M., \& Akomaye A. U. (2017). The impact of educational facilities on students' teaching/learning process in Abeokuta, Ogun State, Nigeria: Need for counselling approaches. European Journal of Education Studies, 3(9), 611-626. https://doi.org/10.5281/zenodo.998534

Bora, S., Bhalerao, Y., Goyal, A., Chakrabarti, D., Chen, D., Bao, N., Niu, X., \& Garg, A. (2019). Computation of safety design indexes of industry vehicle operators based on the reach angle, the distance from elbow to ground and the popliteal height. International Journal of Industrial Ergonomics, 71, 155-164. https://doi.org/10.1016/j.ergon.2019.03.005

Chan, C. T. (2009). Do portable classrooms impact teaching and learning?. Journal of Educational Administration, 7(3), 290-304. https://doi.org/10.1108/09578230910955746

Ekundayo., \& Timilehin, H. (2012). School facilities as correlates of students achievement in the affective and psychomotor domains of learning. European Scientific Journal, 8(6), 208215. https://doi.org/10.19044/esj.2012.v8n6p\%25p

Enjoh, R. M. P. (2018). The impact of school facilities on teaching and learning in presbyterian secondary schools in the SW of Cameroon. International Journal of Trend in Scientific Research and Development (UTSRD), 2(6), 1427-1437. https://doi.org/10.31142/ijtsrd18887

Ginting, R. (2010). Perancangan produk. Graha Ilmu.

Hanggara, A. S. D., Soegiyanto, \& Sulaiman. (2019). Learning infrastructure facilities for physical education, sports and health public elementary schools. Journal of Physical Education and Sports, 8(1), 26-32. https://journal.unnes.ac.id/sju/index.php/jpes/article/view/26295

Ibrahim, N. M., Osman, M. M., Bachok, S., \& Mohamed, M. Z. (2016). Assessment on the condition of school facilities: Case study of the selected public schools in Gombak District. Procedia - Social and Behavioral Sciences, 222(2016), 228-234. https://doi.org/10.1016/j.sbspro.2016.05.151

Ilomo I., \& Mlavi, B. (2016), The availability of teaching and learning facilities and their effects on academic performance in ward secondary schools in Muheza-Tanzania. International Journal of Education and Research, 4(6), 571-582. http://www.ijern.com/journal/2016/June-2016/ON02.pdf

Ismaila, S. O., Musa, A. I. , Adejuyigbe S. B., \& Akinyemi O. D. (2013). Anthropometric design of furniture for use in tertiary institutions in Abeokuta, South-Western Nigeria. Engineering Review, 33(3), 179-192. https://hrcak.srce.hr/111107

Kallio, J. M. (2018). Participatory design of classrooms: Infrastructuring education reform in K12 personalized learning programs. Journal of Learning Spaces, 7(2), 35-49. http://libjournal.uncg.edu/jls/article/view/1727

Merril, B. M., Morrow, A. S., Altszuler, A. R., Macphee, F. L., Gnagy, E. M., Greiner, A. R., Coles, E. K., Raiker, J. S., Coxe, S., \& Pelham, W. E. (2017), Improving homework performance among children with ADHD: A randomized clinical trial. Journal of Consulting and Clinical Psychology, 85(2), 111-122. https://doi.org/10.1037/ccp0000144

Morieson, L., Murray, G., Wilson, R., Clarke, B., \& Lukas, K. (2018). Belonging in space: Informal learning spaces and the student experience. Journal of Learning Spaces, 7(2), $12-$ 22. http://libjournal.uncg.edu/jls/article/view/1667

Nepal, B., \& Maharjan R., (2015), Effect of school's physical facilities on learning and outcomes of students in Nepal. Journal for Studies in Management and Planning, 1(6), 266-279. https://www.researchgate.net/publication/326539534_Journal_for_Studies_in_Manageme nt_and_Planning_Effect_of_School's_Physical_Facilities_on_Learning_and_Outcomes_ of_Students_in_Nepal 
Renaud, J., Houssin, R., Gardoni, M., \& Armaghan, N. (2019). Product manual elaboration in product design phases: Behavioral and functional analysis based on user experience. $\begin{array}{lllll}\text { International Journal of Industrial Ergonomics, } 71, & 75-83 .\end{array}$ https://doi.org/10.1016/j.ergon.2019.02.003

Wignjosoebroto, S. (2008). Ergonomi studi gerak dan waktu. Guna Widya. 